\title{
PROCESSO DE APRENDIZAGEM BASEANDO NO CICLO DE APRENDIZAGEM: UMA APLICAÇÃO À FORMAÇÃO COOPERATIVISTA
}

\author{
Learn process based on the experimental learning cycle: an application \\ to cooperate training
}

\begin{abstract}
Resumo
O presente trabalho discute os graus de participação a partir da utilização de jogos de empresa e do ciclo de aprendizagem vivencial em cursos de cooperativismo. O curso de cooperativismo foi realizado com dois grupos heterogêneos formados por cooperados e colaboradores das cooperativas COOCAFÉ e SICOOB CREDICAF. Os grupos passaram por 16 horas de formação. Os jogos foram utilizados como ferramenta lúdica para introduzir os assuntos inerentes à formação cooperativista. Os resultados obtidos indicam que os jogos de empresas e o ciclo de aprendizagem vivencial são métodos eficientes quando aplicados juntos e de forma estruturada. A metodologia adotada foi um diferencial do curso, segundo os participantes. Também foi possível identificar uma melhora significativa na organização e na participação do grupo. Esta evolução indica que o processo de ensinoaprendizagem foi efetivo. Neste sentido, foi possível concluir que os participantes construíram um conhecimento, bem como aperfeiçoaram o trabalho em grupo.
\end{abstract}

Palavras-chave: Jogos de empresa, ciclo de aprendizagem vivencial, ensino-aprendizagem.

\begin{abstract}
This present paper discusses levels of participation from the use of company games and experiential learning cycles in Management of Cooperatives courses. The course was made with two heterogeneous groups, composed of cooperative members and collaborators of COOCAFÉ and SICOOB CREDICAF. The groups experienced a 16-hour program. The games were used as a ludic tool to introduce the subjects inherent to a cooperativist formation. The results obtained indicate that the company games and the experiential learning cycles are efficient methods, when used together and in a structured way. The adopted methodology was an important part of the course, according to the participants. It was possible to notice a significant improvement in the organization and participation of the group. This improvement indicates that the learning process was effective. In this sense, it was possible to conclude that the participants built knowledge as well as improved group work.
\end{abstract}

Keywords: Business games, experiential learning cycle, teaching-learning

Recebido: 29/08/2014 Aceito: 21/01/2015

Pablo Murta Baião Albino ${ }^{1}$

${ }^{1}$ Foro Europeo Escuela de Negócio de Navarra, Universidade Federal de Viçosa, Doutor em Ciencias Sociais e Jurídica aplcon-sultores@yahoo.com.br 


\section{Introdução}

om educação, aprendizagem e transferência de tecnologia

os empreendedores podem tornar-se atores de seu próprio desenvolvimento criando oportunidades de negócios viáveis (ALBINO, 2005) . A necessidade de uma formação profissional por parte do pequeno e médio gestor é condição para a sobrevivência e expansão de seu negócio.

Neste sentido, a capacidade de aprendizado a partir da vivência tem sido discutida na literatura. Muitos são os autores que validam o potencial de aprendiza-gem dos jogos quando avaliados segundo a teoria do aprendizado vivencial, pois estes são estruturados de modo a desenvolver um ambiente de grande estímulo emocional ou mesmo permitir incentivar tomadas de decisões estratégicas, mesmo que em um ambiente con-trolado (SAUAIA, 1995; MOTTA; SAUAIA; ZERRENNER, 2009; MELO; PAIXÃO, 2012; RIVERA; DOMENICO; SAUAIA, 2014). Desta forma, a aprendizagem também pode ocorrer em um ambiente de segurança quando são utilizadas empresas ou situações hipotéticas. Outra vantagem apresentada é a possibilidade de uma visão holística da empresa apresentando a interação entre seus stakeholders ou mesmo a exploração das características da personalidade humana ao participar e vencer uma competição através de atitudes destinadas a lograr resultados específicos definidos pelos próprios participantes que superam as regras e normas da atividade.

Neste sentido, a utilização dos jogos de empresa com funções didáticas tem crescido por parte das empresas, que enxergaram neste instrumento uma alternativa para facilitar o treinamento de seu quadro de pessoal (SAUAIA, 1995; MOTTA; MELO; PAIXÃO, 2012). As grandes empresas, ao perceberem, há algum tempo, a necessidade de formação, tem criado suas universidades corporativas, centros de formação continuada, todos eles mantidos pelas empresas (EBOLI; HOUNEAUX; MANCINI, 2005; ALVES; FILHO; MARTINS, 2013). Seguindo esta tendência, as instituições de ensino superior também começaram a incluir os jogos nos seus currículos (MOTTA; MELO; PAIXÃO, 2012).

A diversidade de formas de aprender, principalmen-te quando levamos em conta o que será aprendido, é uma realidade. Neste sentido, habilidades podem ser melhores assimiladas quando adotadas práticas que se aproximam da realidade, ou modelos próximos do ideal, do conhecimento dos resultados e dos esforços positi-vos. Por sua vez, os jogos ou atividades estruturadas não proporcionam, de imediato, desenvolvimento de perspectivas abrangentes. Neste sentido, os métodos de preleção são, provavelmente, mais adequados para este propósito. Entretanto, a aprendizagem vivencial pode facilitar que as pessoas assumam o que aprenderam (CAPE, 2002), ou mesmo desenvolvam seu nível de consciência. Diante das possibilidades e aplicações dos jogos de empresas e o ciclo de aprendizagem vivencial (CAV), o presente trabalho tem como objetivo discutir a aplicação desta metodologia enquanto ferramenta útil na evolução dos níveis de participação em cursos de cooperativismo.

O presente trabalho está estruturado em cinco partes sendo a introdução apresentada acima, o referencial teórico onde é realizada uma breve revisão da literatura que aborda o tema. Em seguida é feita uma descrição da metodologia adotada no trabalho. A parte quatro está formada pelos resultados obtidos no trabalho e a discussão destes. Na ultima parte são trazidas as considerações finais a respeito da utilização dos jogos de empresa e do CAV enquanto método para a aprendizagem da teoria cooperativista.

\section{Referencial Teórico}

A utilização de atividades lúdicas/jogos como técnica de ensino-aprendizagem proporciona o desenvolvimento de habilidades interpessoais, conhecimento e formação gerencial, partir da ação vivenciada (MOTTA, 2003).

Neste sentido, podem ser justificadas as técnicas de ensino-aprendizagem baseadas nas atividades lúdicas nas quais os participantes são incentivados a desenvolver atividades dirigidas por um facilitador/instrutor, sempre com o objetivo de aprender, relacionando estas atividades às competências necessárias na sua atividade cotidiana.

Os argumentos apresentados por Freire (1977), sobre o processo de aprendizagem também estão dirigidos à adoção de métodos lúdicos de aprendizagem. O autor comenta que, só aprende aquele que se apropria do aprendido, ou seja, aquele que tem condições de transformar o aprendido, que é capaz de aplicar o aprendido em situações existenciais concretas. Por outro lado, Freire

(1977) chama de "enchido", indivíduos que recebem conteúdo de outros sem perceber que contradizem a própria forma de estar em seu mundo e sem que seja desafiado, não aprende.

Para Ferreira (1999), os métodos de ensino devem ser eleitos de acordo com os objetivos pretendidos, a natureza dos conteúdos, as características dos alunos e a realidade da escola. Neste sentido, para que os métodos sejam efetivos e alcancem sua finalidade é necessário que a metodologia utilizada também esteja em conformidade com os fins propostos e que o educador escolha aquela que melhor orienta seu processo educativo diante da multiplicidade de possibilidade, de abordar um conte-údo, existentes.

Deste modo, aprender fazendo pode ser considerado uma forma efetiva de ensino, pois proporciona uma vivência de situações e problemas, ao mesmo tempo em que, dá a possibilidade de resolver os desafios com seus próprios recursos. Assim, o participante internali-za a informação de maneira duradora, comparando os 
resultados de acordo com as decisões tomadas em que teve participação direta (MOTTA, 2003).

Portanto, toda aprendizagem resulta em uma mudan-ça no comportamento daquele que aprende (PRETTO, 2006). A aprendizagem vivencial pode contribuir neste processo pois, confronta os aprendizes com padrões que representam a essência de uma realidade por meio de um protótipo da situação.É neste processo que são utilizados os jogos de empresa e por meio do CAV é possível catalisar seus resultados, uma vez que as fases são concluídas com êxito encerrando adequadamente cada momento.

\subsection{Jogos de Empresa}

Os jogos ou atividades lúdicas ou brincadeiras têm um papel fundamental no processo educacional. Um ambiente composto pelo bom humor e a espontaneidade promove a confiança e permite que os participantes arrisquem com a possibilidade de se equivocarem (GRAMIGNA, 1993).

Os jogos de empresa permitem que os indivíduos sejam observados enquanto processadores de informações recebidas e tomadores de decisões em um ambiente similar ao de uma organização (SAUAIA; ZERREN-NER, 2009) . Nesse contexto, os jogos, instrumentos de extrema relevância, podem servir para dinamizar, treinar, selecionar ou capacitar pessoas para que estas desenvolvam vantagens competitivas uma vez que os agentes assimilam novos conceitos, o que é alcançado a medida que as vivências dos jogos estejam focadas na realidade em que o participante vive (D'ELBOUX, 2008).

Segundo Pretto (2006), o jogo de empresa é uma simulação do ambiente empresarial, tanto em seus aspectos internos como externos, permitindo uma avaliação e uma análise das possíveis consequências decorrentes das decisões tomadas. O jogo de empresa é uma alter-nativa eficaz para a aprendizagem. Trata se de uma ferramenta difundida no treinamento empresarial. Tendo em conta que a prática, mesmo que simulada, oferece vantagens no que se refere à aprendizagem (MOTTA, 2003; KNABBEN, B; FERRARI, R, 2006). Ao mesmo tempo, a condução das atividades vivenciais dos jogos de empresas favorecem atitudes empreendedoras, o que acaba reforçando o processo de aprendizagem. É neste momento, de equilíbrio entre o racional e o emocional, que os participantes encontram espaços para expor seus sentidos e superar limites (GRAMIGNA, 1993, 2007).

Atualmente, existem diversos jogos de empresa em uso nos mais diferentes campos e objetivos. Esta ferramenta tem sido utilizada no treinamento de pessoal, no desenvolvimento de pessoas, na avaliação do potencial, no planejamento, na tomada de decisões ou na formação de administradores (CAPE, 2002; SAUAIA; ZERRENNER, 2009).

\subsection{Ciclo de Aprendizagem Vivencial}

Desde outro ponto de vista, o CAV é o desenvolvimento de competências pessoais em administração de empresas, visando, principalmente a geração de renda, emprego e desenvolvimento econômico (CEFE-INTERNACIONAL, 1998; GRAMIGNA, 2007). O CAV enquanto processo de vivência de situações práticas, é composto por cinco fases que proporcionam um aprendizado baseado nas experiências de cada um. As fases do CAV estão descritas na Tabela 1.

Durante a vivência pode ocorrer excitação e divertimento, bem como conflitos nas interações humanas, situação que é controlada na seguinte fase - relato. As pessoas após vivenciarem uma atividade, estão prontas para compartilhas o que viram e como se sentiram durante o evento.

$\mathrm{O}$ resultado do processo ensino-aprendizagem deve ser pessoas ou grupos com maior grau de consciência e participação, ou seja, aptas a exercer seu papel nas organizações. Para Bordenave (1983), os graus de consciência podem ser medidos através dos níveis de participação

O grau de informação é aquele em que os membros da organização são informados pelos dirigentes a respeito das decisões tomadas. Na consulta facultativa, os participantes podem ser consultados pelos dirigentes e assim poderão dar sugestões para resolver problemas. $\mathrm{Na}$ consulta obrigatória, os participantes devem ser consultados, embora a decisão final seja dos diretores.

Um nível superior de participação ocorre quando os participantes elaboram propostas e recomendam medidas à direção. Outro patamar nesta escala é a co-gestão, na qual a administração da organização é compartilhada mediante mecanismos de co-direção. A delegação se dá quando os participantes têm autonomia em certos campos antes reservados aos dirigentes. $\mathrm{O}$ grau mais alto de participação é a autogestão, na qual o grupo determina seus objetivos, escolhe seus meios e estabelece os controles (BORDENAVE, 1983).

Como o próprio Bordenave apresenta, a evolução nos graus de participação reduz o controle exercido pelos dirigentes, ou seja, uma maior atuação dos sócios implica em uma menor atuação dos diretores ou do conselho de administração. Os graus de participação propostos por

Bordenave (1983), serão verificados em cada atividade a partir das atitudes do grupo e dos resultados alcançados nos jogos propostos. Desta forma, espera se medir a evolução do nível de participação do grupo.

\section{Metodologia}

O presente trabalho é derivado do Programa de Educação Cooperativa e Capacitação Técnica e Gerencial das Cooperativas Agropecuárias das Matas de Minas realizado pela Universidade Federal de Viçosa e finan- 
Tabela 1. As fases do Ciclo de Aprendizagem Vivencial

\begin{tabular}{|c|c|c|}
\hline Fases & Descrição & Objetivos \\
\hline $\begin{array}{l}\text { Vivência (participar da } \\
\text { atividade) }\end{array}$ & $\begin{array}{l}\text { Jogos ou divertimento composto pelas seguintes } \\
\text { atividades: fabricação de produtos, criação de objetos } \\
\text { de arte, elaboração de piadas e anedotas, dramatização, } \\
\text { interações, solução de problemas, feedback, auto- } \\
\text { exposição, fantasia, escolha, comunicação não verbal, } \\
\text { redação, análise de estudos de casos, negociação, } \\
\text { planejamento, competição, confrontação. }\end{array}$ & $\begin{array}{l}\text { Aprendizagem indutiva, } \\
\text { através da descoberta, onde o } \\
\text { que exatamente será } \\
\text { aprendido não pode ser } \\
\text { especificado de antemão. } \\
\text { Desenvolver uma base } \\
\text { comum de dados para a } \\
\text { discussão que se fará em } \\
\text { seguida. }\end{array}$ \\
\hline $\begin{array}{l}\text { Relato (compartilhar } \\
\text { reações e observações) }\end{array}$ & $\begin{array}{l}\text { O relato pode ser facilitado através de: } \\
\text { Registro de dados referentes à produtividade do } \\
\text { grupo, satisfação, confiança, liderança, comunicação, } \\
\text { decisões, sentimentos etc.; } \\
\text { Registro de rápidas associações de ideias, abrangendo } \\
\text { os vários tópicos relacionados à atividade; } \\
\text { Relatos nos subgrupos; } \\
\text { Listas afixadas no quadro contendo dados do grupo; } \\
\text { Giro pelos grupos, com a realização de mini-entrevistas } \\
\text { com os participantes, para que relatem suas } \\
\text { dificuldades e facilidades; } \\
\text { Análise do desempenho do grupo quando da } \\
\text { representação de papeis (coordenador, moderador, } \\
\text { relator, etc.). }\end{array}$ & $\begin{array}{l}\text { Convidar o grupo a } \\
\text { compartilhar } \\
\text { sentimentos e emoções. } \\
\text { Descobrir o que aconteceu } \\
\text { entre os indivíduos, tanto a } \\
\text { nível cognitivo quanto } \\
\text { afetivo, enquanto a atividade } \\
\text { estava se desenvolvendo. }\end{array}$ \\
\hline $\begin{array}{l}\text { Processamento } \\
\text { (dinâmicas de grupo) }\end{array}$ & $\begin{array}{l}\text { A discussão em profundidade é a parte crítica do ciclo } \\
\text { e não pode ser ignorada. O facilitador planeja, } \\
\text { cuidadosamente, esta fase, podendo utilizar: } \\
\text { Roteiro de observações; } \\
\text { Discussão temática de tópicos decorrentes dos } \\
\text { relatórios individuais; } \\
\text { Complementação de sentenças; } \\
\text { Questionários estruturados, relacionados com o tema; } \\
\text { Palavras-chave afixadas em local visível, que possa, } \\
\text { orientar as discussões; } \\
\text { Feedback interpessoal, relativo ao desempenho dos } \\
\text { membros do grupo. }\end{array}$ & $\begin{array}{l}\text { Os participantes reconstroem } \\
\text { os padrões de } \\
\text { comportamento, as interações } \\
\text { da atividade, a partir de } \\
\text { relatos individuais. } \\
\text { Os participantes são levados } \\
\text { a observar o que aconteceu } \\
\text { em termos de dinâmica. }\end{array}$ \\
\hline $\begin{array}{l}\text { Generalizações (inter- } \\
\text { relacionar os } \\
\text { princípios com } \quad 0 \\
\text { Mundo Real) }\end{array}$ & $\begin{array}{l}\text { Os participantes inferem princípios que podem ser } \\
\text { s aplicados em sua realidade, a partir da atividade: } \\
\text { o Fantasia - imaginar situações do dia-a-dia; } \\
\text { Análise individual - questionar sobre as habilidades } \\
\text { adquiridas com a atividade; } \\
\text { Palavras-chave - tópicos que servem de subsídios para } \\
\text { generalizações; } \\
\text { Complementa sentenças - completar frases. }\end{array}$ & $\begin{array}{l}\text { Apresentar e debater as } \\
\text { generalizações apresentadas } \\
\text { pelo grupo de forma oral e } \\
\text { visual. } \\
\text { Facilitar a aprendizagem. }\end{array}$ \\
\hline $\begin{array}{l}\text { Aplicação (planejar } \\
\text { comportamentos) }\end{array}$ & $\begin{array}{l}\text { r Momento em que os participantes transferem as } \\
\text { generalizações para a situação real. }\end{array}$ & $\begin{array}{l}\text { Planejar comportamentos } \\
\text { mais eficientes. }\end{array}$ \\
\hline
\end{tabular}

Fonte: Manual Jogos de Empresa e o Ciclo de Aprendizagem Vivencial - ICCAPE, 2002. 


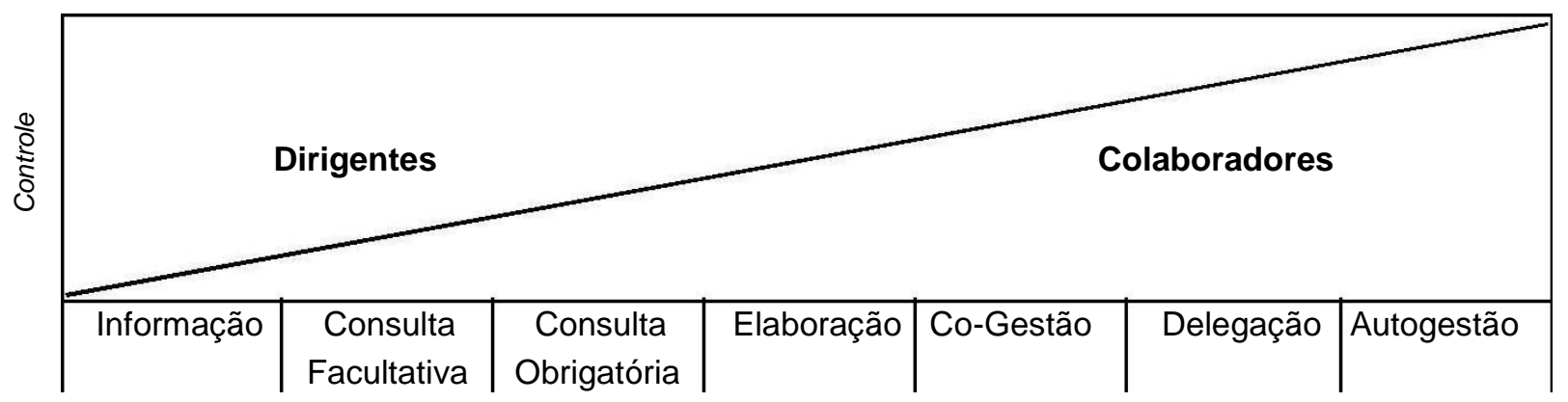

Figura 1. Níveis de participação sugeridos por Bordenave (1983) Fonte: Adaptado de Bordenave, 1983, p.37.

ciado pelo Programa de Extensão Rural (ProExt), do ministério da educação. O programa tem como objetivo geral desenvolver e executar um programa de educação cooperativa e capacitação técnica, econômica e gerencial dos associados das cooperativas de produção de café das Matas de Minas. O Programa é composto por 3 projetos:

Projeto 1 - Curso de Cooperativismo.

Projeto 2 - Curso de atualização técnica em cafeicultura.

Projeto 3 - Curso de economia e administração rural.

O curso de cooperativismo, como mencionado, é um dos projetos do ProExt. Na realização deste foi adotado como ferramenta de trabalho os jogos de empresa apoiado na metodologia ciclo de aprendizagem vivencial (CAV), como meio para realizar o processo de ensino-aprendizagem.

A primeira turma do curso de cooperativismo foi realizada no período de 18 a 20 de fevereiro de 2014, compreendendo uma carga horária de 16 horas e a segunda turma, com igual carga horária foi realizada no período de 11 a 13 de março, do mesmo ano. Ambas contaram com 22 e 19 participantes, respectivamente, distribuídos entre a Cooperativa de Cafeicultores da Região de Lajinha (COOCAFÉ) e Cooperativa de Crédito do Leste de Minas Ltda (SICOOB CREDICAF), que distribuíram as vagas entre seus funcionários e cooperados.

Todos os colaboradores presentes no curso receberam o material gráfico contendo as informações e o conteúdo que seria ministrado. Neste sentido, o curso não apre-sentou diferenças quando comparado a qualquer outro formato de educação ou formação.

A última hora de cada um dos cursos foi utilizado para os avisos finais e a realização da avaliação, por parte dos participantes, sobre os aspectos inerentes ao curso.

Esta avaliação foi o instrumento utilizado para verificar as diferenças entre cada uma das turmas e sobre a qual foram realizadas as análises que seguem.

A evolução do comportamento gerencial e maturidade dos grupos foi mapeada segundo os níveis de participação (informação, consulta facultativa, consulta obrigatória, elaboração/recomendação, co-gestão, delegação e auto-gestão), propostos por Bordenave (1983). A partir desta proposta, foi possível discutir a evolução dos grupos nos processos de tomada de decisão e na sua evolução enquanto agentes capazes de exercerem um papel ativo na gestão da cooperativa. Neste sentido, o diferencial do trabalho consiste na forma pela qual o conteúdo foi abordado. Para isso a equipe técnica utilizou quatro jogos de empresa, sendo um jogo para cada um dos quatro módulos previsto no curso de cooperativismo.

Os jogos têm como finalidade explorar as formas de tomada de decisão, para analisar o perfil do grupo ou individual, além de ampliar os conhecimentos sobre o funcionamento de uma organização em um ambiente simulado. Os jogos realizados e seus respectivos objetivos são apresentados na Tabela 2.

Os quatro jogos utilizados no curso de cooperativismo foram desenvolvidos nas Filipinas, melhorados pela Deutsche Gesellschaftfür Technische Zusammenarbeit (GTZ) e adaptados para a realidade brasileira pelo Instituto Centro de Capacitação e Apoio ao Empreendedor (ICCAPE), localizado em Belo Horizonte/MG.

\section{Resultados e discussão}

Um dos objetivos dos facilitadores foi ministrar cursos onde os colaboradores pudessem interagir, expor suas opiniões e ideias além de compartilhar seus conheci-mentos de maneira mais simples e dinâmica. Além do aprendizado, os colaboradores também assumiram o compromisso de implementar os conteúdos aprendidos, conhecer a metodologia e reaplicá-la em suas organiza-ções cooperativas.

Um primeiro resultado identificado nas avaliações realizadas pelos colaboradores está relacionado ao número de cooperados participantes dos cursos. Entre 
Tabela 2. Lista de Jogos, objetivos, aplicação e tempo de realização (Parte 01)

\begin{tabular}{|c|c|c|}
\hline Jogos & Objetivos Básicos & Objetivos Adicionais \\
\hline $\begin{array}{l}\text { 1. Construção } \\
\text { da Ponte }\end{array}$ & $\begin{array}{l}\text { Identificar a importância do planejamento para a realização de } \\
\text { uma tarefa em grupo; } \\
\text { Identificam condutas mais apropriadas para o trabalho em } \\
\text { equipe; }\end{array}$ & $\begin{array}{l}\text { Desenvolver habilidades de liderança; } \\
\text { Compreender alguns conceitos básicos de qualidade e produtividade; } \\
\text { Compreender que falar não significa estar sendo ouvido; }\end{array}$ \\
\hline $\begin{array}{l}\text { J. Jogo dos } \\
\text { Cabides }\end{array}$ & $\begin{array}{l}\text { Vivenciar e analisar situações de interdependência entre os } \\
\text { diferentes recursos - humanos e materiais - dentro de } \\
\text { organizações; } \\
\text { Analisar os diferentes estilos de liderança, formais ou não } \\
\text { formais, que ocorrem em grupos, de acordo com a situação, } \\
\text { prioridade e emergência das ações e cumprimento de } \\
\text { objetivos; } \\
\text { Explorar os aspectos que interferem de maneira positiva ou } \\
\text { negativa na realização de tarefas em grupo; } \\
\text { Perceber a importância da visão sistêmica; }\end{array}$ & $\begin{array}{l}\text { Examinar os comportamentos uns dos outros, como reações ao } \\
\text { fracasso, autoconfiança e persistência; }\end{array}$ \\
\hline \multicolumn{2}{|c|}{$\begin{array}{l}\text { 3. Empresa de Perceber a importância do desenvolvimento de habilidades } \\
\text { Participação operacionais e de liderança, necessárias ao trabalho de } \\
\text { equipes; } \\
\text { Refletir sobre estilos de liderança e as condutas mais produtivas } \\
\text { de gerentes e líderes, na elaboração de planejamento, na } \\
\text { condução da operacionalização de tarefas, gerenciamento e } \\
\text { monitoramento de planos de trabalho; }\end{array}$} & $\begin{array}{l}\text { Analisar as características do comportamento empreendedor, que } \\
\text { favorecem o posicionamento individual em organizações; } \\
\text { Refletir sobre procedimentos e operações internas, a uma } \\
\text { organização, que garante o alcance de resultados otimizados; } \\
\text { Explorar a importância do gerenciamento e monitoramento de ações } \\
\text { que conduzam à manutenção constante e superação dos níveis de } \\
\text { qualidade, em todos os momentos que pressupõe a relação cliente x } \\
\text { fornecedor, dentro das organizações (gerência de processos); } \\
\text { Examinar os comportamentos uns dos outros, como reações ao } \\
\text { fracasso, autoconfiança e persistência; }\end{array}$ \\
\hline
\end{tabular}

4. Jogo das Analisar seu próprio comportamento de resolução de Desenvolver estratégias apropriadas para resolução de problemas;

Balas problemas;

Comparar estratégias individuais e em grupo;

Conhecer os elementos da resolução produtiva de problemas;

Fonte: Manual de Jogos de Empresa e CAV, 2002

os presentes, em ambos os cursos, $23,53 \%$ eram cooperados, $17,65 \%$ eram supervisores de unidade comercial. Além desses, também estiveram presentes, analista de organização sistemas e métodos, analista de recursos humanos, auxiliar administrativo, consultor técnico, professora e relações públicas com $5,88 \%$ de participação para cada um deles.

A maioria dos colaboradores, nos dois cursos de cooperativismo, afirmam ter encerrado os cursos motivados a repassar as informações ministradas para seus pares. Os resultados apresentados indicam que, $76,47 \%$ e $63,16 \%$, no primeiro e no segundo grupo, respectivamente, se comprometeram a transmitir o conteúdo do curso, sejam eles cooperados ou colaboradores. Ao mesmo tempo, o restante de cada grupo declarou que estavam motivados com os temas e que aplicariam o conteúdo aprendido no dia a dia da Cooperativa. Esta resposta dos cooperados e colaboradores indica o estado motivacional ao final do curso. Neste sentido os jogos e a metodologia parecem ter cumprido seu papel deixando os participantes prontos para compartilhar o que vivenciaram.

Outra preocupação no curso foi a de que, ao longo do mesmo, fossem apresentados conteúdos que estivessem de acordo com a realidade vivenciada pelo grupo em seu ambiente de trabalho. Neste sentido, as avaliações indicam que, no primeiro grupo $88,24 \%$ dos participan-tes perceberam uma estreita relação entre o conteúdo ministrado e a realidade vivida na cooperativa.

Já no segundo grupo este índice foi ainda maior com $94,74 \%$ dos colaboradores identificando semelhanças entre as vivências, seus resultados e a realidade local. Este resultado é um forte indício da efetividade dos jogos de empresa bem como do CAV enquanto métodos de ensino aprendizagem, uma vez que cumprem com seu objetivo de levar os participantes a uma reflexão da realidade a partir de atividades lúdicas.

A respeito da qualidade do conteúdo abordado, no primeiro encontro, $58,82 \%$ dos colaboradores o classificou 
Tabela 2. Lista de Jogos, objetivos, aplicação e tempo de realização (Parte 02)

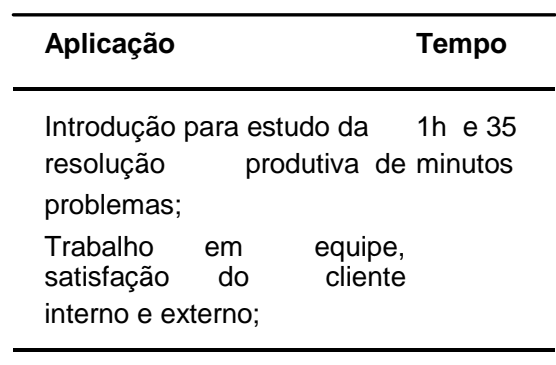

Desenvolvimento de $1 \mathrm{he} 10$

competências empresariais; minutos

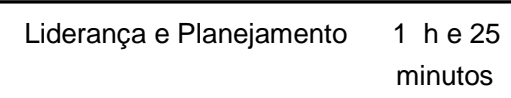

Liderança e Planejamento $\begin{array}{r}1 \mathrm{~h} \text { e } 20 \\ \text { minutos }\end{array}$

Fonte: Manual de Jogos de Empresa e CAV, 2002

como muito bom, outros $23,53 \%$ classificaram o conteúdo como bom e $11,76 \%$ classificou como excelente. O segundo grupo fez uma melhor avaliação quando o assunto foi o conteúdo abordado no curso e $74 \%$ responderam que o conteúdo foi excelente e $26 \%$ acharam o conteúdo

muito bom. Neste sentido pode ser identificada uma decisão acertada a escolha dos jogos que foram adotados nos cursos como mecanismo para trabalhar os temas inerentes a uma organização cooperativa.

Quando perguntados sobre a adequação da carga horária com relação ao conteúdo do curso, no primeiro grupo,

$52,94 \%$ dos colaboradores responderam que a carga horária foi muito boa, $41,18 \%$ responderam que foi boa e $5,88 \%$ responderam que a carga horária foi excelente. Por sua vez a avaliação do segundo grupo foi melhor onde $57,89 \%$ dos colaboradores responderam que a relação carga horária e conteúdo foi excelente, $31,58 \%$ responderam que a carga horária foi muito boa e 10,
$53 \%$ responderam que foi boa. Percebe-se que a carga horária, nos dois cursos, foi adequada para a aplicação do conteúdo. Ainda nesta pergunta, haviam outras duas alternativas, regular e ruim, as quais, não foram utiliza - das. Neste sentido, os resultados do trabalho indicam que uma carga horária de 16 horas é adequada para ministrar cursos de cooperativismo para um público heterogêneo.

A respeito da metodologia, as avaliações de ambos os grupos foram boas, porém o segundo grupo segue sua tendência avaliando o curso de uma forma me-lhor quando comparado aos resultados obtidos pelo primeiro. A primeira avaliação classificou o curso da seguinte forma: $58,82 \%$ indicaram a metodologia como sendo excelente, $39,29 \%$ disseram que a metodologia foi muito boa e $5,88 \%$ respondeu que a metodologia foi boa. No segundo grupo, $84,47 \%$ dos colaboradores responderam que a metodologia utilizada foi excelente e $10,53 \%$ a classificou como muito boa. Além disso, os participantes das duas turmas foram unânimes quando perguntados se a metodologia aplicada melhora ou não a organização do grupo. Todos responderam que o método de trabalho contribuiu para a evolução e aprendizado do grupo. Este resultado vem reforçar o que tem sido constatado pelas respostas de ambos os grupos, que os jogos associados ao CAV promovem o aprendizado em um curso de cooperativismo.

Neste sentido, o trabalho de Bordenave (1983), apoia estes resultados uma vez que pode ser identificada a evolução dos participantes. Os argumentos apresenta-dos indicam uma evolução progredindo de informação a autogestão.

Colaborador C: “...faço uma comparação entre a construção da ponte com Rochdale no momento do surgimento da primeira cooperativa. O cooperativismo surgiu de uma necessidade comum, a sobrevivência e a sustentabilidade..."

Estes são argumentos apresentados pelos participantes durante a realização da primeira atividade (construção da ponte). No jogo das balas, ultima atividade realizada no curso, após cumprir com os objetivos, os colaboradores fizeram alguns relatos que também indicam evolução no grau de participação:

Colaborador X: “... cumprimos a meta, mas relaxamos, se houvesse uma continuação o resultado poderia ser diferente"

Colaborador Y: “... existiu hierarquia, mas todos puderam contribuir dando sugestões, conversando..."

Colaborador Z: “... nas atividades da cooperativa devemos ter um olhar crítico, a exemplo do jogo das balas que foi realizado com sucesso, mas poderíamos ter ido além, ou seja, alcançado um resultado melhor e não ter nos acomodado..." 
Alcançar o grau de autogestão foi importante, principalmente quando recordamos que uma das atribuições dos participantes é a de replicar as atividades junto a seus pares nas suas respectivas organizações cooperativas.

Ao mesmo tempo, como prevê Pretto (2006), foi possível constatar que houve mudança no comportamento dos colaboradores derivado do aprendizado.

Outro aspecto importante é referente à atuação dos facilitadores do curso, uma vez que este recurso também afeta na aprendizagem. Entre os participantes da primeira turma, os facilitadores foram avaliados como excelente por $29,41 \%$ dos participantes, $64,71 \%$ consideraram os facilitadores muito bons e 5,88\% disseram que a atuação dos facilitadores foi boa.

$\mathrm{Na}$ segunda turma, os facilitadores foram melhor avaliados, uma vez que, $63,16 \%$ dos participantes responderam que os facilitadores tiveram uma atuação excelente, e 36,85\% responderam que a atuação dos facilitadores foi muito boa. Este resultado proveniente da percepção dos participantes a respeito dos facilitadores contribuiu como catalizador do processo ensinoaprendizagem, pois a sinergia construída durante o curso favoreceu a relação entre participantes e facilitadores.

Participantes também foram perguntados sobre o atendimento de suas expectativas no curso, e $17,65 \%$, na primeira turma, afirmou ter sido excelente enquanto

$41,18 \%$ respondeu que o curso foi muito bom e bom e. Já na segunda turma, 57,89\% responderam que o curso foi excelente em relação ao atendimento de suas expectativas, $31,58 \%$ responderam que o curso foi muito bom, e 5,26\% responderam que o curso foi bom, outros $5,26 \%$ não responderam. Aqui cabe um aprofundamento para que seja possível identificar que aspectos motivaram os participantes a realizarem esta avaliação, uma vez que os objetivos do curso foram cumpridos e, ao mesmo tempo alguns colaboradores não se mostraram satisfeitos com este resultado.

Com a intenção de conhecer a opinião dos colaboradores sobre a execução prática do curso, estes foram perguntados sobre seu próprio comportamento. As respostas indicam que, na primeira turma, $76,47 \%$ dos colaboradores terminaram o curso motivado a tenta-rem implementar os conteúdos aprendidos, além de compreender a metodologia a ponto de replicá -la na cooperativa. Outros $17,65 \%$ responderam que estão motivados com os temas abordados e que aplicarão no dia a dia da cooperativa. A segunda turma apresentou um resultado similar, onde $63,16 \%$ dos colaboradores responderam que estavam motivados a implementar os conteúdos e aprender a metodologia, além de replicar o conteúdo na cooperativa. Outros 36,84\% responderam que estavam motivados com os temas e os aplicará no dia a dia da cooperativa. Este resultado confirma o argumento de Freire (1977), no qual o autor afirma que aprende aquele que se apropria do ensinado a ponto de poder colocar em prática o aprendido.
Os colaboradores também foram perguntados a respeito da adequação do conteúdo do curso e sua abordagem e a semelhança deste com a realidade da cooperativa. Neste sentido, na primeira turma, 88,24\% dos participantes responderam que o conteúdo condizia com sua realidade e $11,76 \%$ responderam que não. Já na segunda turma, o número de colaboradores que responderam que o curso condiz com sua realidade, aumentou para $94,74 \%$, sendo que $5,26 \%$ responderam que não. Neste sentido, três colaboradores apontaram que o conteúdo abordado não condiz com sua realidade. Devido à diversidade e heterogeneidade dos participan-tes, uma vez que estes eram cooperados, funcionários e técnicos agrícolas, este resultado pode ser entendido, ao mesmo tempo, ajuda a explicar os resultados encon-trados quando foram perguntados sobre o atendimento das expectativas.

Dentre os aspectos que mais foram observados pelos colaboradores das duas turmas, a metodologia utilizada no curso foi o mais citado. Entre os grupos, $15,38 \%$ e $17 \%$, respectivamente, apontaram ser a metodologia utilizada o aspecto que mais o marcou na realização do curso. Alguns colaboradores também relataram que se sentiram à vontade com a maneira dinâmica na qual o curso foi passado, e também pela simplicidade e inte-ração dos facilitadores.

Os resultados alcançados foram satisfatórios uma vez que os colaboradores, além de comentarem sobre as qualidades do método, dos jogos utilizados e a satisfação ao final do curso, também demonstraram amadurecimento do grupo durante a realização das atividades.

\section{Considerações finais}

A associação entre a academia, através da Universidade Federal de Viçosa (UFV) e a ferramenta de formação utilizada nos cursos de cooperativismo proporcionou uma aprendizagem satisfatória, tanto por parte daque-les que estiveram realizando o curso quando da equipe responsável pela execução das atividades propostas.

Com a realização dos jogos e a metodologia proposta, durante o curso, observa-se uma melhora significativa na organização e evolução na participação enquanto grupo. Esta evolução demonstra que o processo de ensinoaprendizagem foi efetivo uma vez que os parti-cipantes mudaram de maneira considerável sua forma de interagir passando de uma postura informadora para uma atuação interativa, fundamental para alcançar a autogestão em organizações cooperativas.

Finalmente, foi possível concluir que os cursos ministrados foram de grande proveito para os participantes, pois esses tiveram chance de aprender mais sobre sua área de atuação, bem como aperfeiçoar o trabalho em grupo, podendo assim, multiplicar esse aprendizado. $\mathrm{O}$ Curso de Cooperativismo ajudará também no desen- 
volvimento e na execução do programa de educação cooperativa e capacitação técnica, econômica e gerencial dos associados das cooperativas participantes do curso.

Neste sentido, é importante agradecer a participação e a motivação dos cooperados e colaboradores da COOCAFÉ e CREDICAFE, que estiveram presentes nos cursos de cooperativismo pois, sem a participação destes seria impossível a realização deste trabalho.

O trabalho também apresentou limitações, como o tamanho do grupo que participou do curso em relação ao total de cooperados, além do critério de seleção dos participantes. Esta pequena mostra pode ter sido causadora de um viés nos resultados alcançados. Outra limitação que deve ser considerada é a realização das atividades dentro da Universidade, um ambiente supostamente controlado e munido de todas as ferramentas necessárias para se alcançar o objetivos do curso.

Neste sentido, os trabalhos futuros devem buscar sanar estas limitações realizando os cursos nas localidades próximas às residências dos cooperados com a possibilidade de participação aberta a todo o quadro social, para que desta forma a diversidade e a aleatoriedade entre os participantes passa ser um fator de robustez nos resultados. Além desta questão, seria interessante identificar a formação de redes de informação entre os participantes dos cursos, ou seja, identificar e medir o grau de integração gerado a partir da vivência dos jogos.

\section{Referências}

ALBINO, P. M. B. Viabilidade Econômica desafios dos empreendimentos de economia popular e solidária (NESOL/USP, Ed.)Educação políticas e Economia Solidária. IV Encontro de Economia Solidária. Anais...São Paulo: NESOL/USP, 2005

ALVES, C. DE S.; FILHO, P. A. L. DE S.; MARTINS, T. A. Contribuiçao dos jogos empresariais dentro da política da universidade corporativa nas organizações1o Seminário internacional de integraçao e desenvolvimento regional. Anais...2013

BORDENAVE, J. E. D. O que é participaçao. 1a. ed. Sao Paulo: [s.n.]. p. 87

CAPE, C. Manual do Multiplicador. Belo Horizonte: [s.n.].

CEFE-INTERNACIONAL. Competency-based Economies through Formation of EnterpriseManual for Trainers. [s.l: s.n.].

D’ELBOUX, P. C. Jogos de Empresa. Anuário de Produção Acadêmica Docente, v. XII, n. 2, p. 201 214, 2008.
EBOLI, M.; HOUNEAUX, F. J.; MANCINI, S. Breve panorama da educaçao corporativa no Brasil: Apresentaçao de resultados de pesquisaEncontro da Associaçao Nacional dos Programas de Pós Graduaçao em Administração. Anais...2005

FERREIRA, A. ABC das Finanças. São Paulo: [s.n.].

FREIRE, P. Pedagogia do oprimido. Rio de Janeiro: [s.n.]. p. 218

GRAMIGNA, M. R. M. Ciclo de Aprendizagem Vivencial. São Paulo: [s.n.].

GRAMIGNA, M. R. M. Jogos de empresa e técnicas vivênciais. Person Pre ed. Sao Paulo: 2o edição, 2007. p. 142

KNABBEN, B, C.; FERRARI, R, A. A simulação estratégica no processo de ensino/ aprendizagem os jogos de empresa.

MOTTA, F. F. C. Uma proposta para o ensino da gestão do capital de giro em pequenas e médias empresas través de jogos de empresa. [s.l.] Universidade Federal da Bahia, 2003.

MOTTA, G. DA S.; MELO, D. R. A.; PAIXÃO, R. B. O jogo de empresas no processo de aprendizagem em administraçao: o discurso coletivo de alunos. Revista de Administraçao Contemporânea, v. 16, n. 3, p. $342-359,2012$.

PRETTO, F. N. Pedagogia participativa na formação de administradores. [s.l.] Universidade de São Paulo, 2006.

RIVERA, J. RAMON D.; DOMENICO, S. MA. R.; SAUAIA, A. C. A. Influência da Dissimilaridade de Valores Individuais no Resultado de Times de Alta Gerência: um estudo em laboratório de gestão. Revista Brasileira de Gestão de Negócios, v. 16, n. 50, p. $60-74,2014$

SAUAIA, A. C. A.; ZERRENNER, S. A. Jogos de Empresas e Economia Experimental: um Estudo da Racionalidade Organizacional na Tomada de Decisao. Revista de Administraçao Contemporânea, v. 13, n. 2, p. $189-209,2009$.

SAUAIA, A. CARLOS A. Satisfação e aprendizagem em jogos de empresas. [s.1.] Universidade de Sao Paulo, 1995. 
